\title{
Metastatic clival chordoma: a case report of multiple extraneural metastases following resection and proton beam radiotherapy in a 5-year old boy
}

\author{
*Martin J. Rutkowski, MD, ${ }^{1}$ Harjus S. Birk, BS, ${ }^{1}$ Matthew D. Wood, MD, PhD, ${ }^{2}$ Arie Perry, MD, ${ }^{2}$ \\ Theodore Nicolaides, MD, ${ }^{1,3}$ Christopher P. Ames, MD, ${ }^{1}$ and Nalin Gupta, MD, PhD1,3 \\ Departments of ${ }^{1}$ Neurological Surgery, ${ }^{2}$ Pathology, and ${ }^{3}$ Pediatrics, University of California, San Francisco, California
}

\begin{abstract}
The authors report the case of a 5-year-old boy in whom extraneural metastases developed 5 years after he underwent an occipitocervical fusion and transoral approach to treat a clival chordoma without local recurrence. Following primary resection, the patient's postoperative course was complicated by recurrent meningitis secondary to CSF leak, which responded to antibiotics, and communicating hydrocephalus, for which a ventriculoperitoneal shunt was placed. The patient then underwent postoperative proton beam radiotherapy. Five years following his initial presentation, surveillance imaging revealed a new asymptomatic lung mass for which the patient underwent thoracotomy and resection of the mass. Histological examination of the lung mass revealed findings consistent with a de-differentiated chordoma, confirming extraneural metastasis from the original tumor without evidence of local recurrence. Chest wall and scalp metastases subsequently developed, and the patient was started on an adjuvant chemotherapy regimen that included imatinib and rapamycin followed by subsequent nivolumab and an EZH2 inhibitor for recurrent, disseminated disease. Despite this patient's remote and distant metastases, primary gross-total resection for chordoma remains a critical treatment objective, followed by proton beam radiotherapy. This case illustrates the importance of interval posttreatment imaging and the emerging potential to treat chordoma with molecularly targeted therapies.

https://thejns.org/doi/abs/10.3171/2017.1.PEDS16549
\end{abstract}

KEY WORDS chordoma; clival; intracranial; metastasis; recurrence; proton beam; transoral; oncology

$\mathrm{C}$ LIVAL chordoma is a rare tumor that can occur in both adults and children. Only 300 new cases are diagnosed annually in the United States, and these lesions are typically seen in adults between the ages of 45 and 70 years (median age 58.5 years) at diagnosis. ${ }^{34}$ Epidemiological data from one population-based study suggest that the incidence of chordomas is 0.08 per 100,000 , with less than $5 \%$ arising in patients younger than 40 years of age ${ }^{41}$ In adult patients, clival chordomas account for $0.2 \%$ of all intracranial tumors, ${ }^{33}$ and among the pediatric population, chordomas represent only $0.15 \%$ of all intracranial tumors. ${ }^{2}$

The clinical presentation of these tumors is highly dependent on anatomical location. Patients with sacral chordomas present with back pain, radiculopathy, lowerextremity pain, and/or urinary incontinence. ${ }^{22}$ In cases of intracranial chordomas, patients present with headaches and cranial neuropathies leading to symptoms such as diplopia, facial numbness, dysphonia, and dysphagia. ${ }^{23}$
Limited evidence indicates that pediatric chordomas may be more aggressive than adult chordomas, $7,9,15,16,24,26,31$, $40,48,53,55,62,63$ perhaps due to the relative proportion of intracranial tumors in children relative to adults, ${ }^{24}$ more aggressive pathological features such as high p53 immunoreactivity (suggestive of a TP53 gene mutation), higher MIB-1 labeling index, and higher rates of necrosis and cytological atypia. ${ }^{62}$ Furthermore, loss of the tumor suppressor gene INII has been implicated as a marker of a more aggressive biology in pediatric chordomas. ${ }^{44,62}$ Pathological classification also plays a role in determining prognosis; in one of the larger series reported, Borba and colleagues reported on 79 cases of intracranial chordoma in which pathological examination revealed classical, chondroid, and atypical rates of $64.6 \%, 13.5 \%$, and $22.5 \%$, associated with mortality rates of $23.1 \%, 37.5 \%$, and $100 \%$, respectively. ${ }^{9}$ Similar to these findings, 2 other large case series on pediatric patients found an association between atypical pathology and worsened survival. ${ }^{51,62}$

* Dr. Rutkowski and Mr. Birk contributed equally to this work. 
While rates of metastasis range from $3 \%$ to $48 \%$ among all clival, sacral, and vertebral chordomas in adults, estimates of metastasis in children indicate a possible bimodal distribution, with patients under 5 years of age demonstrating a rate as high as $58 \%$, compared with just $8.5 \%$ for patients who are 5 years of age or older. ${ }^{26}$ Pulmonary metastases appear to be most common in the pediatric population, followed by the lymphatic system, bone, liver, kidney, adrenal glands, and the heart. ${ }^{9}$ Atypical pathology has also been associated with metastatic tumors. ${ }^{9,16,55} \mathrm{Nev}$ ertheless, clinical, pathological, and molecular predictors of metastasis remain unclear.

We describe the case of a comprehensive management strategy in a 5-year-old boy who presented with a clival chordoma and underwent occipitocervical fusion, transoral gross-total resection, and adjuvant proton beam radiotherapy (PBRT). Despite success with control of the intracranial disease, the patient developed remote and distant pulmonary, bony, and soft-tissue metastases.

\section{Case Report}

\section{History and Examination}

A 5-year-old boy presented with a 2-month history of increasing positional neck pain, dyspnea, and dysphagia. His parents reported a concomitant decline in appetite and oral intake, decreased gustatory sensation, and headaches occurring at night and upon awakening. Mild speech hesitation and dysarthria were also noted. There were no visual changes, vertigo, gait ataxia, seizures, or loss of consciousness. Neurological examination was notable for left hypoglossal neuropathy with tongue protrusion to the left, but the patient was otherwise neurologically intact. His medical and surgical histories were notable only for a previously excised atretic, undescended testicle. His family and social histories were unremarkable, and his only medications included over-the-counter analgesics.

\section{Imaging}

A CT brain scan revealed a 2-cm hyperdense, bi-lobed mass arising from the basion and abutting the left vertebrobasilar junction, exerting mild mass effect on the medulla. There was no evidence of hydrocephalus. An MRI scan confirmed the presence of a mass at the junction of the interior clivus and tip of the odontoid process, arising from the basion and extending posteriorly toward the medulla (Fig. 1). The mass measured approximately $2.2 \times 0.9$ $\times 1.1 \mathrm{~cm}$ and was associated with abnormal nonenhancing $\mathrm{T} 2$ hyperintensity within the interspace between the inferior clivus and dens process. There was intrinsic T1 hyperintensity and FLAIR hyperintensity at the lesion's inferior border, without vessel compromise or bony involvement of the atlas, axis, or clivus.

\section{Operation}

Prior to a transoral resection for the skull base tumor, the patient underwent a planned occiput- $\mathrm{C} 2$ fusion. A C1-2 Harm's fusion with an occipital plate and rods was performed. Navigation and fluoroscopy were used to confirm accurate placement of all instrumentation. A corticocancellous graft obtained from the right iliac crest
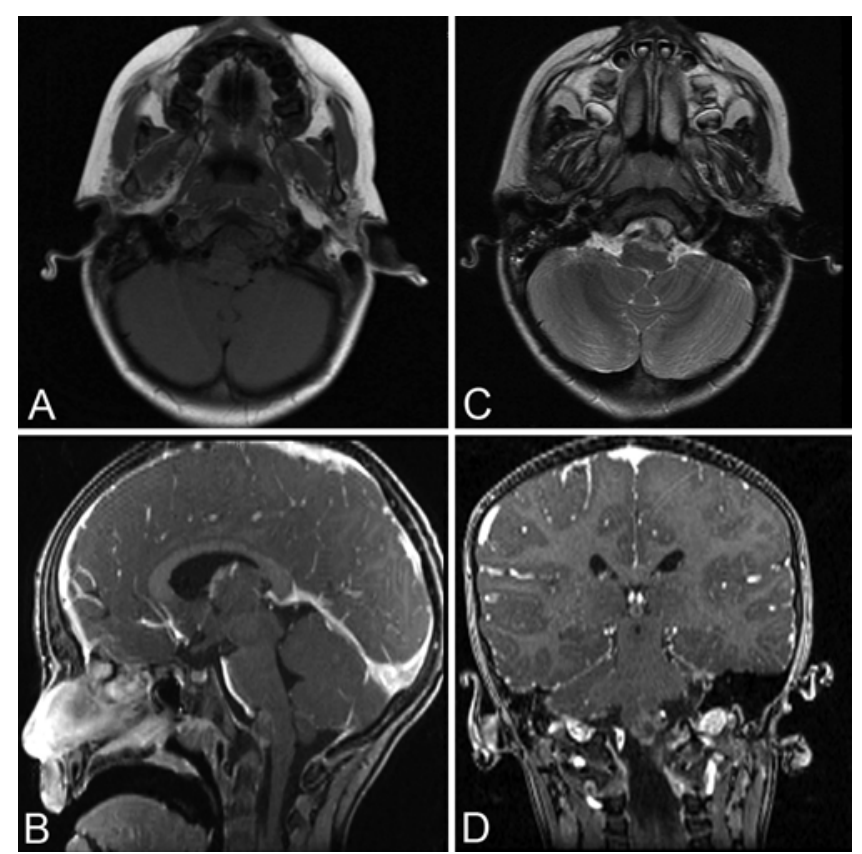

FIG. 1. Brain MRI with T1-weighted precontrast (A), T1-weighted postcontrast (B and $\mathbf{D}$ ), and T2-weighted (C) sequences demonstrating a 2.2- $\mathrm{cm}$ bi-lobed mass arising from the basion with abutment of the left vertebrobasilar arterial junction and mild mass effect on the left ventral medulla without associated T2 hyperintensity.

was placed over the decorticated region from the occiput to C-2 to facilitate a bony arthrodesis. Seven days later, the patient underwent elective tracheostomy to facilitate second-stage transoral approach.

Thirteen days following his occipitocervical fusion, the patient underwent a planned transoral resection of the intra- and extradural clival mass. The $\mathrm{C}-1$ anterior ring was identified and the dens and clivus removed, ultimately exposing the soft-tissue lesion that was then sent for biopsy and confirmed to be a clival chordoma. Microscopic and endoscopic magnification ensured both gross-total intraand extradural resection, and dural margins were assessed for any residual tumor attachment. During repair, Duragen was placed into the bony space and filled with autologous fat graft material obtained from the periumbilical region. Fibrin glue and layered closure of the posterior oropharynx concluded the procedure. A lumbar drain was then placed. Postoperative imaging revealed gross-total resection of the primary clival chordoma (Fig. 2).

\section{Pathological Findings}

Histological analysis revealed a classic chordoma composed of small epithelioid cells with a vacuolated cytoplasm superimposed on a basophilic mucin-rich background, with minimal cytological atypia and no significant mitotic activity (Fig. 3). The chordoma exhibited scattered foci of necrosis with an accompanying component of reactive lymphocytes. On immunohistochemical analysis, tumor cells showed strong positivity for cytokeratin and epithelial membrane antigen (EMA) and tested negative for S-100 immunoreactivity (Fig. 3). The MIB-1 labeling index was estimated at $10 \%$. Immunohistochemistry for brachyury was not performed. 

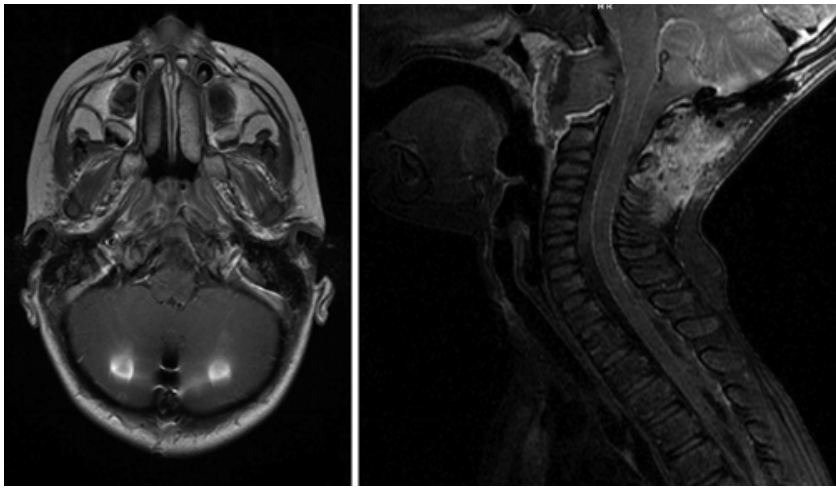

FIG. 2. Postoperative brain T1-weighted postcontrast axial (left) and sagittal (right) MRI sequences demonstrating interval gross-total resection of the patient's clival chordoma.

\section{Postoperative Course}

The patient's initial postoperative course was uneventful, and his tracheostomy was successfully weaned. He was discharged to home with no neurological deficits. However, 2 weeks following the tumor resection, he was readmitted for meningitis. A peripheral blood smear and lumbar puncture (CSF with 6400 white blood cells) demonstrated bacterial meningitis with Klebsiella pneumonia, for which he received vancomycin and ceftriaxone for 7 days. A cisternogram showed a CSF leak in the region where the clival mass was resected, with an associated dural defect. The patient underwent operative repair of the CSF leak, a nasal septal flap was mobilized, and a lumbar drain was placed. There was a persistent leak, and 1 week later an external ventricular drain was placed. Despite initial resolution, the CSF leak persisted after clamping of the extraventricular drain (EVD). Ultimately, a right frontal ventriculoperitoneal (VP) shunt was placed. Following discharge, the patient underwent adjuvant PBRT.

\section{Follow-Up}

Two years later, on a routine MR imaging study, an area of enhancement was noted in the midclival region. Due to concern for local tumor recurrence, he was admitted to the hospital and taken to the operating room for endoscopic transnasal and transoral biopsies, which were negative for tumor recurrence. Pathological examination of the tissue demonstrated bone and fibroconnective and fibrovascular tissue without any evidence of recurrent chordoma. Unfortunately, the procedure was complicated by recurrent CSF leak and meningitis. His VP shunt was removed and replaced 2 weeks later after a course of antibiotics.

\section{Development of Metastases}

During surveillance imaging, a routine chest radiograph demonstrated a new, asymptomatic, right pulmonary lesion 4.6 years following his initial resection. A PET/CT scan demonstrated an isolated right lower lobe mass measuring $3.8 \times 2.9 \mathrm{~cm}$ (Fig. 4), for which he underwent a wedge resection at an outside facility. The histology of the lung mass was reviewed at the University of California, San Francisco, and confirmed to be metastatic, poorly differentiated chordoma composed of pleomorphic
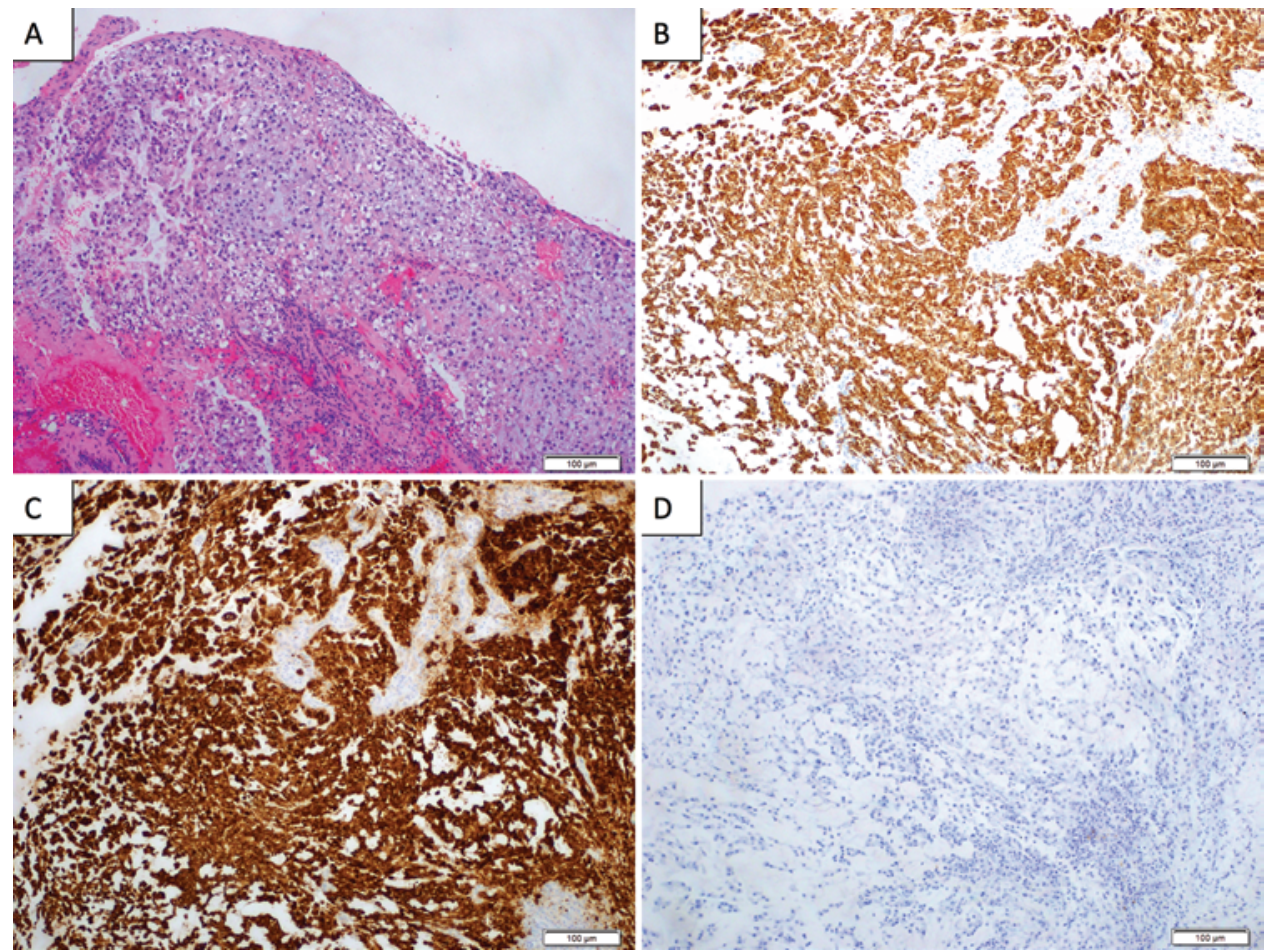

FIG. 3. H \& E-stained section (A) of the clival mass revealing a neoplasm composed of neoplastic epithelioid cells with foamy vacuolated cytoplasm on a basophilic mucoid background, with minimal atypia and no significant mitotic activity. Tumor cells are immunoreactive for cytokeratin (B) and EMA (C) but are not reactive to antibodies against S-100 protein (D). Figure is available in color online only. 


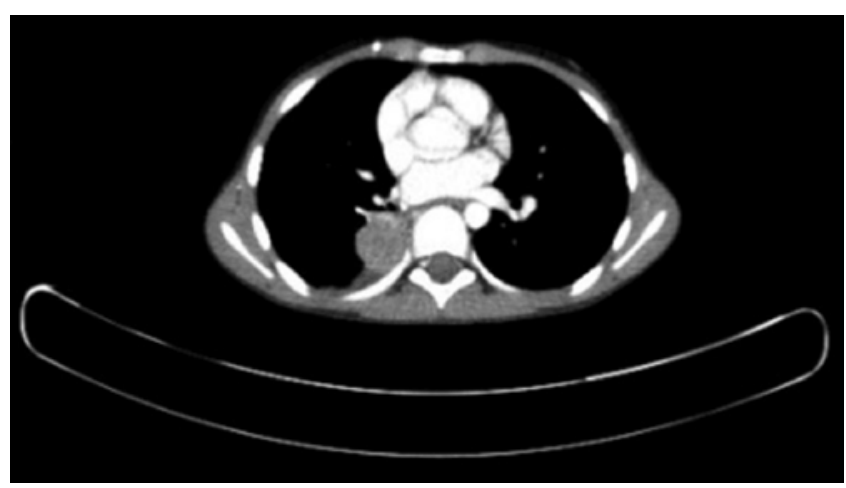

FIG. 4. PET/CT scan revealing a prominent right lower lobe chordoma metastasis 4.6 years after initial transoral gross-total resection.

epithelioid cells with vesicular chromatin and significant mitotic activity (Fig. 5). The immunohistochemical profile matched that of the original tumor, with strong immunopositivity for pancytokeratin and EMA and no staining for S-100 (not shown). Additional immunohistochemical profiling showed strong nuclear positivity for brachyury and nuclear INI-1 in tumor cells, the latter a frequent alteration in de-differentiated chordoma (Fig. 5). ${ }^{44}$ A tumor sample was sent to Caris Life Sciences for CLIA-approved genetic and immunohistochemical analysis in the hope of identifying targetable alterations in this unusual recurrence. After testing for 592 biomarkers as part of the panel, the tumor showed loss of PTEN, high expression of PD-L1, and loss of INI-1 (SMARCB1/SNF5/BAF47), confirming the INI-1 immunohistochemistry result.

In the following months, the patient developed multiple metastases in his right chest wall and right calvaria, for which he was started on imatinib and sirolimus given evidence that the mammalian target of rapamycin (mTOR) pathway is activated in many chordomas and combination therapy enhances treatment response in advanced disease. ${ }^{58}$ He subsequently demonstrated tumor regression and pain improvement. However, 9 months after resection of the pulmonary metastases, the patient developed a right frontal scalp mass with drainage and early breakdown of skin adjacent to his right frontal VP shunt. To prevent exposure of the shunt and allow healing of the scalp, the mass was surgically removed and a scalp rotational flap used to close the soft-tissue defect. The histological appearance of the mass was consistent with metastatic chordoma. The patient was subsequently started on nivolumab due to the tumor's high expression of PD-L1, and he experienced further reductions in his thoracic pain. Six months later, despite lasting pain reduction in response to 2 doses of nivolumab, he developed a new and discrete painful chest mass. Nivolumab was stopped and an EZH2 inhibitor started due to loss of INI-1 seen on immunohistochemistry and genetic testing; he is currently on this novel therapy and awaiting follow-up to assess response.

\section{Discussion}

We describe an unusual case of a metastatic clival chordoma in a 5-year-old boy following resection and adjuvant PBRT. His case is unique for the delayed fashion in which he developed metastases distant from his primary clival resection site despite gross-total resection and adjuvant PBRT, and the high morbidity associated with his transoral approach, including the need for multiple CSF leak repairs, CSF diversion with a right frontal VP shunt, and recurrent episodes of meningitis. His clinical course highlights the need for close follow-up with interval surveillance imaging-performed at least annually-given the relatively low rates of progression-free and overall survival observed as early as 5 years following initial treatment, and in particular in cases of subtotal resection. . $^{1,23,28-30 \text {, }}$ 46,47 Additionally, the development of systemic symptoms should prompt a low threshold for pan-imaging to rule out metastases. Removal of all macroscopic tumor tissue and adjuvant postoperative radiotherapy does not prevent tumor recurrence and progression. ${ }^{19}$

It has been widely reported that patients with untreated chordomas have 5- and 10-year overall survival rates of $68 \%$ and $35 \%$, respectively. ${ }^{39,41}$ Mean survival for pediatric patients with untreated chordoma is only 28 months following symptom onset. ${ }^{41}$ In patients treated surgically with gross-total resection or subtotal resection, the 5-year overall survival rates have been shown to increase to $82 \%$ and $52 \%$, respectively, indicating that complete resection may have a significant impact on long-term survival. ${ }^{1}$ With resection and adjuvant external-beam radiotherapy, mean survival increases to $3.6-6.6$ years..$^{41}$

\section{Proton Beam Radiotherapy}

PBRT is an attractive adjuvant therapy in pediatric patients. It is highly effective in reducing the irradiated tumor volume given that there is no exit dose within a few millimeters distal to the tumor site, ${ }^{37}$ and protons affect specific populations of tumor cells without adversely affecting neighboring tissue, unlike photons used in other radiotherapy techniques. ${ }^{47} \mathrm{PBRT}$ also offers an advantage because of the reduced dose required to reach deeper tissues (Bragg peak). ${ }^{17,21,49}$

Studies investigating the role of adjuvant PBRT on median survival rates in patients with chordomas have reported 5- and 10-year median survival rates of $78 \%$ and $63 \%$, respectively, following resection plus adjuvant PBRT.,20 Another series of 13 patients treated with PBRT for chordomas demonstrated an overall survival rate of $67 \%$ at 5 years. ${ }^{30}$ The 5-year local control rates following PBRT for chordoma range from $47 \%$ to $73 \%$ and ultimately increase with decreasing tumor size. ${ }^{46,47}$

Nevertheless, despite the widespread prevalence of PBRT for residual or recurrent disease, it does not appear to be superior to other radiation modalities in either 5-year progression-free survival or overall survival; one metaanalysis comparing PBRT to Gamma Knife radiosurgery, carbon ion radiotherapy, and LINAC fractionated therapy found no significant differences beyond a lower 5-year progression-free survival for Gamma Knife radiosurgery versus carbon ion radiotherapy. ${ }^{19}$ Another review on PBRT for skull base chordomas estimated a rate of $60 \%$ progression-free survival following PBRT versus $50 \%$ for fractionated external-beam radiotherapy, concluding there was little evidence to support one adjuvant radiation modality over another. ${ }^{11}$

While PBRT is increasingly used as an adjuvant treat- 

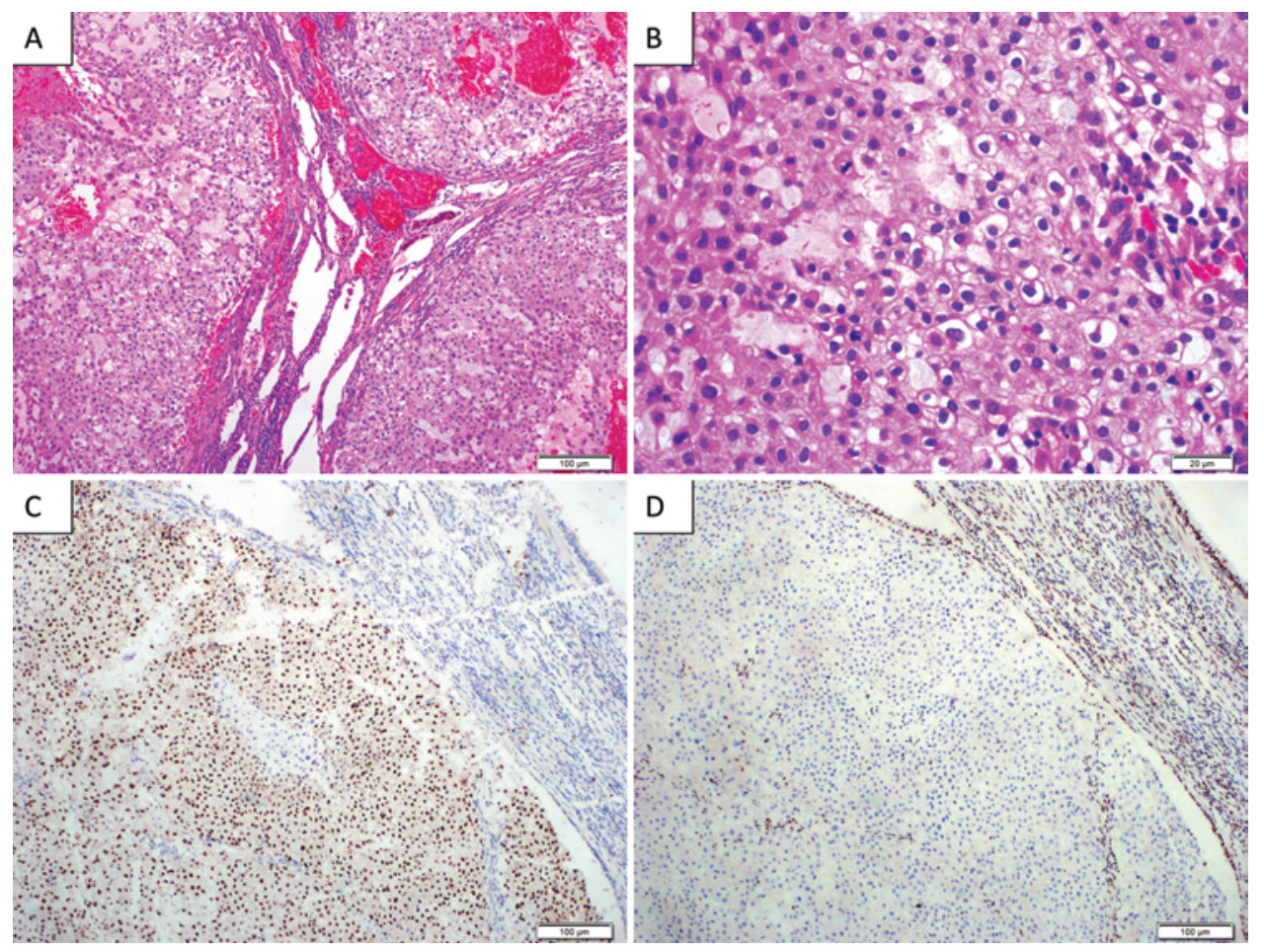

FIG. 5. A and B: H \& E-stained sections of the lung mass showing a poorly differentiated epithelioid neoplasm composed of cells with pleomorphic, hyperchromatic nuclei and brisk mitotic activity (up to 10 mitotic figures in $10 \mathrm{hpf}$ ). C: The tumor cells show strong nuclear reactivity for brachyury. D: The tumor cell nuclei are negative for INI-1. Figure is available in color online only.

ment for long-term control of chordoma, the literature remains very limited regarding rates of metastatic disease, particularly in pediatric patients. In one pediatric series of PBRT for chordoma, local tumor control was maintained in 6 of 10 patients, with no tumor recurrence or metastases on follow-up at 5 years posttreatment. ${ }^{28,29}$ Benk et al. ${ }^{8}$ compared the outcomes of 18 pediatric patients (ages 4-18) with skull base and cervical spinal chordomas who underwent adjuvant PBRT, in which the 5-year overall survival rate was $68 \%$. Interestingly, $3(16.7 \%)$ of the 18 children developed distant metastases: 1 patient with local tumor control developed bilateral pulmonary metastases 22 months after cervical chordoma resection, while the other 2 patients developed pulmonary metastases at 15 and 22 months postresection. ${ }^{8}$ By comparison, the authors of a series of adult patients with intracranial chordoma who underwent resection followed by PBRT reported a metastatic rate of 27\%.60 Overall, the limited amount of published data makes it difficult to compare rates of metastasis among the different radiation modalities, and no obvious superior modality has been established for local progression free-survival and overall survival when comparing proton- and photon-based radiotherapy. ${ }^{11,19}$

Finally, it is important to note that a pediatric chordoma patient being treated with PBRT is at increased risk of vasculopathy and secondary neoplasms ${ }^{42,43}$ and for this reason, it is worthwhile to perform annual surveillance MRI and MR angiography. Furthermore, unlike adults, for whom the chance of treatment-related metastasis increases within 2-4 years postirradiation, metastases may develop 5-10 years postirradiation in children, ${ }^{20,43}$ corroborating our assertion that long-term interval surveillance imaging is critical for tumor detection. Neuroendocrine axis screening is also essential throughout the duration of PBRT to ensure the integrity of pituitary gland function.

\section{Medical Therapy}

Evidence on the effectiveness of chemotherapy for clival chordoma remains largely experimental and anecdotal, with most reports in the literature coming in the form of case reports and small case series. ${ }^{18}$ Chemotherapeutic regimens have been used to varying degrees of success, including ifosfamide/doxorubicin,${ }^{54}$ ifosfamide/ etoposide, ${ }^{18}$ cisplatin/bleomycin/vinblastine, ${ }^{5}$ and a prospective trial of 9-nitro-camptothecin. ${ }^{15}$ The spectrum of molecular alterations identified in chordomas ${ }^{6}$ has led to scattered reports of inhibitors against epidermal growth factor receptor, $27,26,38,56,59$ platelet-derived growth factor receptor, ${ }^{13,57}$ mTOR, ${ }^{50,58}$ and vascular endothelial growth factor ${ }^{4}$ being used in their treatment, with almost all publications reporting some level of partial response and symptom relief.

We used a regimen of chemotherapeutic agents targeted to the molecular alterations frequently found in chordomas and those specific to this patient's tumor. Given frequent dysregulation of mTOR and platelet-derived growth factor receptor in chordoma, ${ }^{13,58}$ sirolimus and imatinib were started at the patient's first presentation of disseminated disease. Upon further disease progression, nivolumab was selected due to the tumor's observed overexpression of PD-L1. Though not studied in chordoma specifically, nivolumab has demonstrated efficacy in the treatment of non-small cell lung cancer, ${ }^{10,12}$ renal cell carcinoma, ${ }^{45}$ and 
melanoma, ${ }^{35,52,61}$ in which upregulation of PD-L1 levels is seen. While this proved highly effective after 2 doses, the patient's development of a new thoracic metastasis led to use of the INI-1 inhibitor EZH2. Loss of INI-1 in chordoma has been associated with pediatric tumors ${ }^{3,62}$ and a more aggressive phenotype. ${ }^{25,44} \mathrm{EZH} 2$, short for enhancer of zeste homolog 2, is an enzymatic subunit of a larger complex known as Polycomb repressive complex 2 which helps methylate lysine 27 of histone $\mathrm{H} 3$ and silence gene transcription. Overexpression, gain of function, and loss of function mutations of EZH2 have been implicated in multiple cancer types including breast, prostate, glioblastoma, lung, and myeloproliferative disorders. ${ }^{32}$ Importantly, a number of preclinical and Phase I and II trials are underway using EZH2 inhibitors in these various cancer types, ${ }^{32}$ underscoring the possibility that our molecularly targeted approach may show efficacy in the treatment of this patient's chordoma.

\section{References}

1. Aguiar Júnior S, Andrade WP, Baiocchi G, Guimarães GC, Cunha IW, Estrada DA, et al: Natural history and surgical treatment of chordoma: a retrospective cohort study. Sao Paulo Med J 132:297-302, 2014

2. Allen AM, Pawlicki T, Dong L, Fourkal E, Buyyounouski M, Cengel K, et al: An evidence based review of proton beam therapy: the report of ASTRO's emerging technology committee. Radiother Oncol 103:8-11, 2012

3. Antonelli M, Raso A, Mascelli S, Gessi M, Nozza P, Coli A, et al: SMARCB1/INI1 involvement in pediatric chordoma: a mutational and immunohistochemical analysis. Am J Surg Pathol 41:56-61, 2017

4. Asklund T, Sandström M, Shahidi S, Riklund K, Henriksson R: Durable stabilization of three chordoma cases by bevacizumab and erlotinib. Acta Oncol 53:980-984, 2014

5. Azzarelli A, Quagliuolo V, Cerasoli S, Zucali R, Bignami P, Mazzaferro V, et al: Chordoma: natural history and treatment results in 33 cases. J Surg Oncol 37:185-191, 1988

6. Barry JJ, Jian BJ, Sughrue ME, Kane AJ, Mills SA, Tihan T, et al: The next step: innovative molecular targeted therapies for treatment of intracranial chordoma patients. Neurosurgery 68:231-241, 2011

7. Becker LE, Yates AJ, Hoffman HJ, Norman MG: Intracranial chordoma in infancy. Case report. J Neurosurg 42:349-352, 1975

8. Benk V, Liebsch NJ, Munzenrider JE, Efird J, McManus P, Suit H: Base of skull and cervical spine chordomas in children treated by high-dose irradiation. Int J Radiat Oncol Biol Phys 31:577-581, 1995

9. Borba LA, Al-Mefty O, Mrak RE, Suen J: Cranial chordomas in children and adolescents. J Neurosurg 84:584-591, 1996

10. Borghaei H, Paz-Ares L, Horn L, Spigel DR, Steins M, Ready NE, et al: Nivolumab versus docetaxel in advanced nonsquamous non-small-cell lung cancer. N Engl J Med 373:1627-1639, 2015

11. Brada M, Pijls-Johannesma M, De Ruysscher D: Proton therapy in clinical practice: current clinical evidence. J Clin Oncol 25:965-970, 2007

12. Brahmer J, Reckamp KL, Baas P, Crinò L, Eberhardt WEE, Poddubskaya E, et al: Nivolumab versus docetaxel in advanced squamous-cell non-small-cell lung cancer. N Engl J Med 373:123-135, 2015

13. Casali PG, Messina A, Stacchiotti S, Tamborini E, Crippa F, Gronchi A, et al: Imatinib mesylate in chordoma. Cancer 101:2086-2097, 2004

14. Chetty R, Levin CV, Kalan MR: Chordoma: a 20-year clini- copathologic review of the experience at Groote Schuur Hospital, Cape Town. J Surg Oncol 46:261-264, 1991

15. Chugh R, Tawbi H, Lucas DR, Biermann JS, Schuetze SM, Baker LH: Chordoma: the nonsarcoma primary bone tumor. Oncologist 12:1344-1350, 2007

16. Coffin CM, Swanson PE, Wick MR, Dehner LP: Chordoma in childhood and adolescence. A clinicopathologic analysis of 12 cases. Arch Pathol Lab Med 117:927-933, 1993

17. Colli B, Al-Mefty O: Chordomas of the craniocervical junction: follow-up review and prognostic factors. J Neurosurg 95:933-943, 2001

18. Dhall G, Traverso M, Finlay JL, Shane L, Gonzalez-Gomez I, Jubran R: The role of chemotherapy in pediatric clival chordomas. J Neurooncol 103:657-662, 2011

19. Di Maio S, Temkin N, Ramanathan D, Sekhar LN: Current comprehensive management of cranial base chordomas: 10year meta-analysis of observational studies. J Neurosurg 115:1094-1105, 2011

20. Donahue B: Short- and long-term complications of radiation therapy for pediatric brain tumors. Pediatr Neurosurg 18:207-217, 1992

21. Erkmen CP, Barth RJ Jr, Raman V: Case report: Successful treatment of recurrent chordoma and bilateral pulmonary metastases following an 11-year disease-free period. Int J Surg Case Rep 5:424-427, 2014

22. Feldenzer JA, McGauley JL, McGillicuddy JE: Sacral and presacral tumors: problems in diagnosis and management. Neurosurgery 25:884-891, 1989

23. Forsyth PA, Cascino TL, Shaw EG, Scheithauer BW, O'Fallon JR, Dozier JC, et al: Intracranial chordomas: a clinicopathological and prognostic study of 51 cases. J Neurosurg 78:741-747, 1993

24. Habrand JL, Datchary J, Bolle S, Beaudré A, de Marzi L, Beccaria K, et al: Chordoma in children: Case-report and review of literature. Rep Pract Oncol Radiother 21:1-7, 2016

25. Hasselblatt M, Thomas C, Hovestadt V, Schrimpf D, Johann P, Bens S, et al: Poorly differentiated chordoma with SMARCB1/INI1 loss: a distinct molecular entity with dismal prognosis. Acta Neuropathol 132:149-151, 2016

26. Hoch BL, Nielsen GP, Liebsch NJ, Rosenberg AE: Base of skull chordomas in children and adolescents: a clinicopathologic study of 73 cases. Am J Surg Pathol 30:811-818, 2006

27. Hof H, Welzel T, Debus J: Effectiveness of cetuximab/gefitinib in the therapy of a sacral chordoma. Onkologie 29:572574,2006

28. Hug EB, Loredo LN, Slater JD, DeVries A, Grove RI, Schaefer RA, et al: Proton radiation therapy for chordomas and chondrosarcomas of the skull base. J Neurosurg 91:432439, 1999

29. Hug EB, Sweeney RA, Nurre PM, Holloway KC, Slater JD, Munzenrider JE: Proton radiotherapy in management of pediatric base of skull tumors. Int J Radiat Oncol Biol Phys 52:1017-1024, 2002

30. Igaki H, Tokuuye K, Okumura T, Sugahara S, Kagei K, Hata M, et al: Clinical results of proton beam therapy for skull base chordoma. Int J Radiat Oncol Biol Phys 60:11201126, 2004

31. Kaneko Y, Sato Y, Iwaki T, Shin RW, Tateishi J, Fukui M: Chordoma in early childhood: a clinicopathological study. Neurosurgery 29:442-446, 1991

32. Kim KH, Roberts CWM: Targeting EZH2 in cancer. Nat Med 22:128-134, 2016

33. Koutourousiou M, Snyderman CH, Fernandez-Miranda J, Gardner PA: Skull base chordomas. Otolaryngol Clin North Am 44:1155-1171, 2011

34. Lanzino G, Dumont AS, Lopes MB, Laws ER Jr: Skull base chordomas: overview of disease, management options, and outcome. Neurosurg Focus 10(3):E12, 2001

35. Larkin J, Chiarion-Sileni V, Gonzalez R, Grob JJ, Cowey 
CL, Lao CD, et al: Combined nivolumab and ipilimumab or monotherapy in untreated melanoma. N Engl J Med 373:23 34,2015

36. Launay SG, Chetaille B, Medina F, Perrot D, Nazarian S, Guiramand J, et al: Efficacy of epidermal growth factor receptor targeting in advanced chordoma: case report and literature review. BMC Cancer 11:423, 2011

37. Levin WP, Kooy H, Loeffler JS, DeLaney TF: Proton beam therapy. Br J Cancer 93:849-854, 2005

38. Lindén O, Stenberg L, Kjellén E: Regression of cervical spinal cord compression in a patient with chordoma following treatment with cetuximab and gefitinib. Acta Oncol 48:158159, 2009

39. Magrini SM, Papi MG, Marletta F, Tomaselli S, Cellai E, Mungai V, et al: Chordoma-natural history, treatment and prognosis. The Florence Radiotherapy Department experience (1956-1990) and a critical review of the literature. Acta Oncol 31:847-851, 1992

40. Matsumoto J, Towbin RB, Ball WS Jr: Cranial chordomas in infancy and childhood. A report of two cases and review of the literature. Pediatr Radiol 20:28-32, 1989

41. McMaster ML, Goldstein AM, Bromley CM, Ishibe N, Parry DM: Chordoma: incidence and survival patterns in the United States, 1973-1995. Cancer Causes Control 12:1-11, 2001

42. Merchant TE: Proton beam therapy in pediatric oncology. Cancer J 15:298-305, 2009

43. Merchant TE, Wang MH, Haida T, Lindsley KL, Finlay J, Dunkel IJ, et al: Medulloblastoma: long-term results for patients treated with definitive radiation therapy during the computed tomography era. Int J Radiat Oncol Biol Phys 36:29-35, 1996

44. Mobley BC, McKenney JK, Bangs CD, Callahan K, Yeom $\mathrm{KW}$, Schneppenheim R, et al: Loss of SMARCB1/INI1 expression in poorly differentiated chordomas. Acta Neuropathol 120:745-753, 2010

45. Motzer RJ, Escudier B, McDermott DF, George S, Hammers HJ, Srinivas S, et al: Nivolumab versus everolimus in advanced renal-cell carcinoma. N Engl J Med 373:1803-1813, 2015

46. Munzenrider JE, Liebsch NJ: Proton therapy for tumors of the skull base. Strahlenther Onkol 175 (Suppl 2):57-63, 1999

47. Nguyen QN, Chang EL: Emerging role of proton beam radiation therapy for chordoma and chondrosarcoma of the skull base. Curr Oncol Rep 10:338-343, 2008

48. Nolte K: Malignant intracranial chordoma and sarcoma of the clivus in infancy. Pediatr Radiol 8:1-6, 1979

49. Palm A, Johansson KA: A review of the impact of photon and proton external beam radiotherapy treatment modalities on the dose distribution in field and out-of-field; implications for the long-term morbidity of cancer survivors. Acta Oncol 46:462-473, 2007

50. Ricci-Vitiani L, Runci D, D’Alessandris QG, Cenci T, Martini M, Bianchi F, et al: Chemotherapy of skull base chordoma tailored on responsiveness of patient-derived tumor cells to rapamycin. Neoplasia 15:773-782, 2013

51. Ridenour RV III, Ahrens WA, Folpe AL, Miller DV: Clinical and histopathologic features of chordomas in children and young adults. Pediatr Dev Pathol 13:9-17, 2010

52. Robert C, Long GV, Brady B, Dutriaux C, Maio M, Mortier $\mathrm{L}$, et al: Nivolumab in previously untreated melanoma without BRAF mutation. N Engl J Med 372:320-330, 2015
53. Sassin JF, Chutorian AM: Intracranial chordoma in children. Arch Neurol 17:89-93, 1967

54. Scimeca PG, James-Herry AG, Black KS, Kahn E, Weinblatt ME: Chemotherapeutic treatment of malignant chordoma in children. J Pediatr Hematol Oncol 18:237-240, 1996

55. Sibley RK, Day DL, Dehner LP, Trueworthy RC: Metastasizing chordoma in early childhood: a pathological and immunohistochemical study with review of the literature. Pediatr Pathol 7:287-301, 1987

56. Singhal N, Kotasek D, Parnis FX: Response to erlotinib in a patient with treatment refractory chordoma. Anticancer Drugs 20:953-955, 2009

57. Stacchiotti S, Longhi A, Ferraresi V, Grignani G, Comandone A, Stupp R, et al: Phase II study of imatinib in advanced chordoma. J Clin Oncol 30:914-920, 2012

58. Stacchiotti S, Marrari A, Tamborini E, Palassini E, Virdis E, Messina A, et al: Response to imatinib plus sirolimus in advanced chordoma. Ann Oncol 20:1886-1894, 2009

59. Stacchiotti S, Tamborini E, Lo Vullo S, Bozzi F, Messina A, Morosi C, et al: Phase II study on lapatinib in advanced EGFR-positive chordoma. Ann Oncol 24:1931-1936, 2013

60. Weber DC, Malyapa R, Albertini F, Bolsi A, Kliebsch U, Walser M, et al: Long term outcomes of patients with skullbase low-grade chondrosarcoma and chordoma patients treated with pencil beam scanning proton therapy. Radiother Oncol 120:169-174, 2016

61. Weber JS, D’Angelo SP, Minor D, Hodi FS, Gutzmer R, Neyns B, et al: Nivolumab versus chemotherapy in patients with advanced melanoma who progressed after anti-CTLA-4 treatment (CheckMate 037): a randomised, controlled, openlabel, phase 3 trial. Lancet Oncol 16:375-384, 2015

62. Yadav R, Sharma MC, Malgulwar PB, Pathak P, Sigamani E, Suri V, et al: Prognostic value of MIB-1, p53, epidermal growth factor receptor, and INI1 in childhood chordomas. Neuro Oncol 16:372-381, 2014

63. Yadav YR, Kak VK, Khosla VK, Khandelwal N, Radotra BD: Cranial chordoma in the first decade. Clin Neurol Neurosurg 94:241-246, 1992

\section{Disclosures}

Dr. Ames consults for Stryker, Medtronic, and DePuy; receives royalties from Biomet Spine and Stryker; and is a patent holder with Fish \& Richardson, PC.

\section{Author Contributions}

Conception and design: Rutkowski, Birk, Wood, Nicolaides, Gupta. Acquisition of data: Rutkowski, Birk, Wood, Perry, Nicolaides, Ames. Analysis and interpretation of data: Rutkowski, Wood, Perry, Nicolaides, Gupta. Drafting the article: Rutkowski, Birk, Nicolaides, Gupta. Critically revising the article: all authors. Reviewed submitted version of manuscript: all authors. Approved the final version of the manuscript on behalf of all authors: Rutkowski. Study supervision: Rutkowski.

\section{Correspondence}

Martin J. Rutkowski, Department of Neurological Surgery, University of California, San Francisco, 505 Parnassus Ave., M-779, San Francisco, CA 94143. email: martin.rutkowski@ucsf.edu. 